The 16th Economic International Conference

New Challenges and Opportunities for the Economy 4.0, May 7-8th, 2020, Suceava, Romania

\title{
Awareness Level of IFRS among Managers in Romania
}

\author{
Irina Diana IORDACHE
}

$\underline{\text { https://doi.org/10.18662/lumproc/ncoe4.0.2020/14 }}$

How to cite: Iordache, I.D. (2020). Awareness Level of IFRS among Managers in Romania. In C. Nastase (vol. ed.), Lumen Proceedings: Vol. 13. 16th Economic International Conference NCOE 4.02020 (pp. 148-157). Iasi, Romania: LUMEN Publishing House.

https://doi.org/10.18662/lumproc/ncoe4.0.2020/14 


\title{
Awareness Level of IFRS among Managers in Romania
}

\author{
Irina Diana IORDACHE ${ }^{1 *}$
}

\begin{abstract}
An accounting sistem based on IFRS should offer many benefits, both in terms of the presentation and reporting of the financial information, as well as in terms of the decisionmaking process, giving entities the opportunity to use global financial markets in order to raise their capital.

In this context, through this research we wish to identify the perceptions of CEOs of Romanian companies, following the adoption of international financial reporting standards, especially to judge if the application of IFRS facilitated the attraction of external financing sources in Romanian companies .

Most respondents are aware of the advantages to be gained by implementing IFRS. Thus, 96\% of the interviewed managers consider that the main advantages offered by the adoption of IFRS consist, on the one hand, in increasing the level of approval and disclosure of financial information at international level and, on the other hand, in improving the accounting role in the management process. of results. Such benefits should improve the investment process in Romanian companies, as the confidence of potential investors in Romanian companies would increase; a benefit that, at the moment, the Romanian entities seems to not get yet.
\end{abstract}

Keywords: IFRS; stock market; external financing; accounting profession.

\footnotetext{
1 „1 Decembrie 1918" University from Alba Iulia, Romania, irina.iordache07@gmail.com 


\section{Introduction}

The exponential evolution of modern society requires the continuous improvement of financial-accounting information. It must be built in such a way as to meet, on one hand, the management's needs for decision-making process and, on the other hand, the information requirements of the company's partners.

It is generally known that the presentation of credible information serves primarily the financial purposes of a company, in the sense that the presentation of inadequate information leads to a distortion of the image of the company's financial condition. Therefore, we would like to highlight this aspect, in the sense that obtaining erroneous financial information is not only a violation of legal accounting or tax provisions, but is also a misinformation at the level of financial balance both long-term and shortterm, with serious consequences for both the internal and external environment of the company.

In this regards our research mainly pursued the following objectives:

- first, we wanted to check if the adoption of IFRS has lead to an improved external financing in Romanian companies;

- secondly, we've examined if the job of the accounting profession has improved in the management activity after the adoption of IFRS

- thirdly, we have investigated if any additional costs were imposed by the application of IFRS;

\section{Problem Statement}

The globalization is an irreversible and continuous historical reality, which works in the interest of the international community, in which information and knowledge occupy central positions.

In this context, at the global level, the process of integration and harmonization of economies is of increasing interest[1]. The whole process involves on one hand the lifting of restrictions, and on the other hand a series of actions in the harmonization of regulations that facilitate the development of international cooperation, trade, technology transfer and the improvement and accessibility of the international financial-foreign exchange system.

Accounting, like any other component of the economic system, has undergone a series of changes and adaptations in line with the new trend of globalization, harmonization and integration[4]. At the level of Romanian accounting, an attempt was made both to adapt to the regional changes, generated by Romania's accession to the European Union, and as well to the international changes. 
The main role that accounting plays in this process of globalization is to ensure the comparability of economic information. Therefore, many reasons have been found to support the need for unique global financial reporting.

To these globalization requirements, time has shown that IFRS, developed by ICAS and subsequently adopted by the European Commission, have best responded.

Currently, more than 15,000 companies in more than 144 countries have adopted international accounting principles and rules[3]. While these impressive numbers are certainly a success, the pros and cons of applying international accounting standards (IFRS) are still being debated internationally, so the literature is constantly trying to see if there is a real need for financial statements reported according to International Financial Reporting Standards[2].

Reviewing the literature and the research conducted in the past regarding IFRS, on international accounting standards, we deducted that even that each state could set up an accounting according to their desires, this aspect could be an obstacle for external investors and for companies that collaborates with foreign subsidiaries or if the companies are part of financial markets. Hence, it seems that the internationalization of accounting could conduct to global collaboration of companies and to a more effortless understanding of the data presented by companies, but all of this for an undoubtful cost.

Even though there is an interest in the specially designed literature with reference to the IFRS appliance in Romania, nonetheless, the ramification of the phenomenon lacks extended research in the field, conducted from various theoretical and methodological perspectives.

\section{Research Questions/Aims of the research}

In order to achieve the proposed objective, our study started from the following hypotheses:

$>$ H1: Adoption of IFRS has led to an improved external financing in Romanian companies.

$>$ H2: The job of the accountant has increased in the decision-making process after the adoption of IFRS.

$>\mathrm{H} 3$ : The application of IFRS imposes additional costs

\section{Research Methods}

The main objective of this study was to investigate the perception of the professionals involved in the elaboration of the financial statements of 
the companies regarding the benefits the adoption of IFRS may have lead to. The research undertaken by us falls within the scope of applied research and has the following characteristics:

- Descriptive cross-sectional research

- Research method used: survey

- The period in which it was made: July - December 2019.

- Research tool: questionnaire

- Sample consisting of: 87 companies

- Response rate: $63 \%$

In this sense, we proceeded to prepare a study using the statistical survey technique. According to this technique, we used a questionnaire addressed to professionals in the fields: financial-accounting, management, and audit, which included 17 questions, divided into two categories:

- General questions, with the role of building the profile of the respondents.

- Specific questions regarding the perception of professionals regarding the benefits of IFRS

Below we present the most relevant aspects of the research methodology.

\section{Findings}

A first result of our research highlighted that the Romania's IFRS practice resulted from legal obligations, but, more than that, we wanted to know whether an entity will show interest in an IFRS based accounting if the legal requirements do not exist. As such, we have discovered that $53 \%$ of the interviewed CFOs would not implement IFRS if not enacted. As per Figure 1 , there is also a high percentage of responses, $47 \%$, according to which companies would implement IFRS for many other reasons, that are not involving legal obligation, such as: own drive, under the of shareholders, to attract foreign finance.

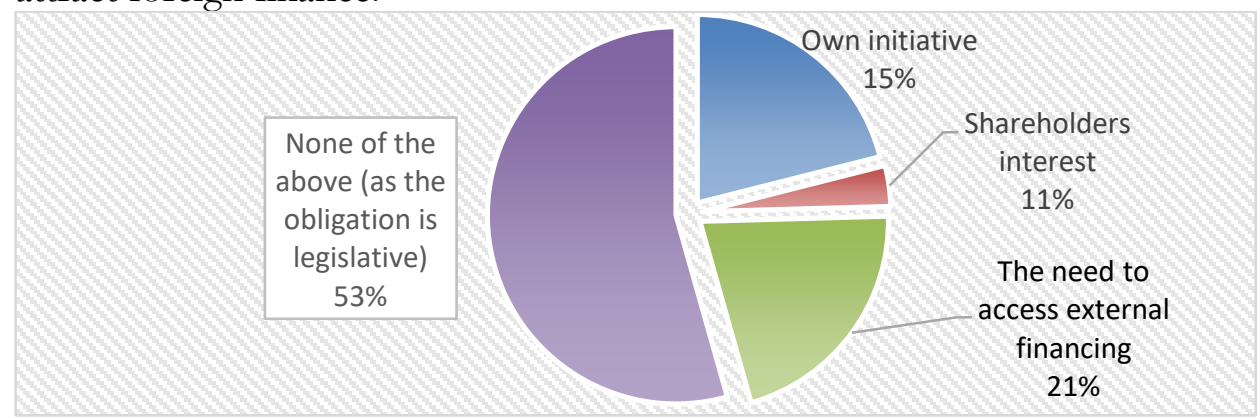

Figure no. 1 Reasons for implementing the IFRS 
Further on, we wished to examine the shareholding structure of the entities that are applying the international financial standards by analysing the entities owned by foreign shareholders versus the entities owned by local shareholders. Thus, it can be observed (figure no. 2) that out of 47 companies, $74.2 \%$ belong to local investors, while $25.8 \%$ belong to foreign investors. It is possible that this capital structure to conduct to a low interest in adopting IFRS at the level of Romanian entities.

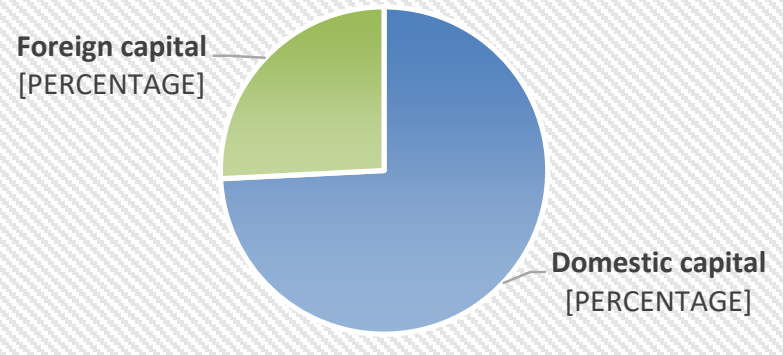

Figure no. 2 Local investors vs. External investors in Romanian entities

In order to test our primary assumption, we wished to learn if the management of the entities in our sample acknowledge that the interest of foreign investors increased after the IFRS implementation.

Thus, in figure 3 it can be observed that entities held by foreign shareholders are benefiting more of external source of financing than the entities held by local investors. Domestic companies wish to have access to this type of sources, but currently in Romania only $26 \%$ of these entities are able to attract external financing frequently and/or occasionally.

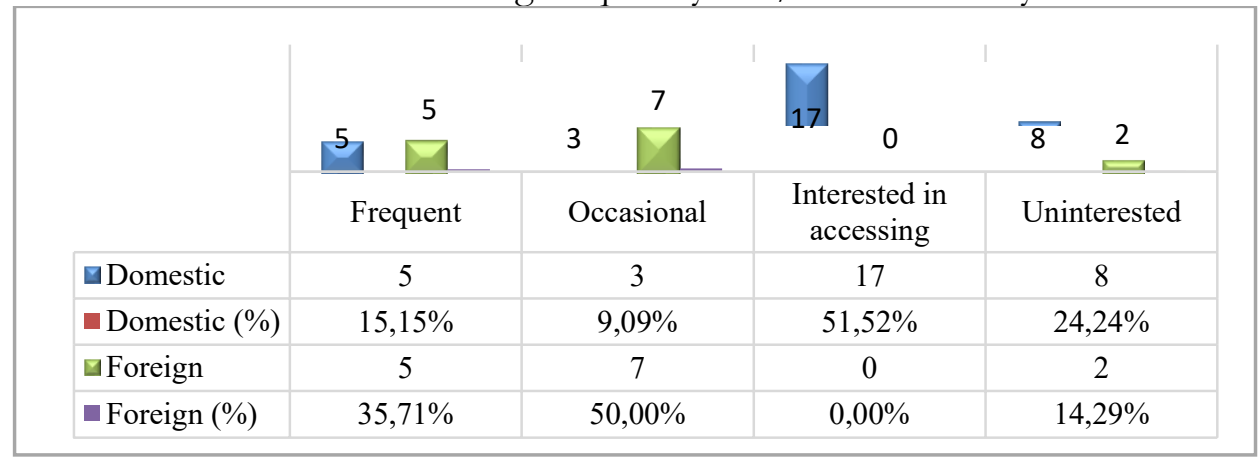

Figure no. 3. Frequency of atracting external finance at the level of Romanian companies 
Furthermore, we have considered that the results of our study will be more precise if we analyse the type of the primary financing source used by the Romanian entities that are applying IFRS. Therefore, according to the results from figure no. 4 , we can conclude that the capital market is not the primary source of financing for our studied entities. It seems that selffinancing comes first and then we found out the capital market being the second source of finance, followed with a slight difference by bank loans and intergroup loans, which usually on the other hand also are associated with loan costs. This behaviour in attracting financing sources seems to be particular for continental states that do not have enough power to attract and satisfy the investors.

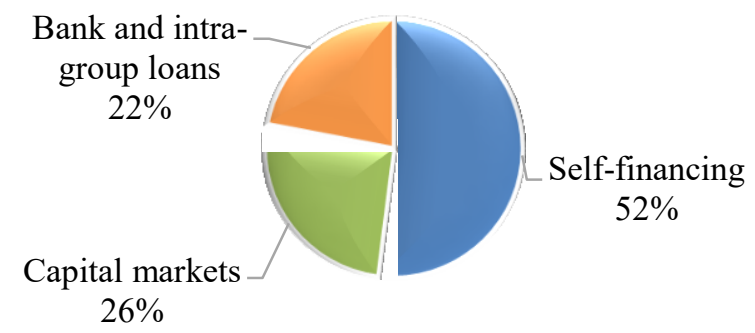

Figure no. 4 The primary financing source used by Romanian entities

In this situation, given our findings, on one hand about legislative requirements as being the main reason for the interviewed mangers for implementing IFRS and on the other hand, the fact that entities owned by domestic investors do not consider that the application of IFRS was sufficient to attract sources of foreign financing, we have all the reasons to not validate assumption no. 1. Furthermore, by associating the response received regarding the relationship between IFRS application and the external financing sources, we found both on figure no. 5 and figure no. 6 (represented further down), that the major motivation for implementing IFRS among Romanian companies is not the necessity for external funding.

To certify the second hypothesis or not, we have investigated manager's perceptions about the benefits associated with IFRS implementation. So, in figure no. 5 it can be observed that the majority of respondents agreed that, after the adoption of IFRS, several benefits were obtained in terms of: intelligibility, transparency, comparability and clarity of financial information, as well as professional openings and opportunities.

Concerning the increasing role of bookkeeping in the management activity, $83 \%$ of the interviewed managers stated that, with the adoption of 
IFRS, accounting data is far more valuable for decision makers. Consequently, we can assume supposition no 2.

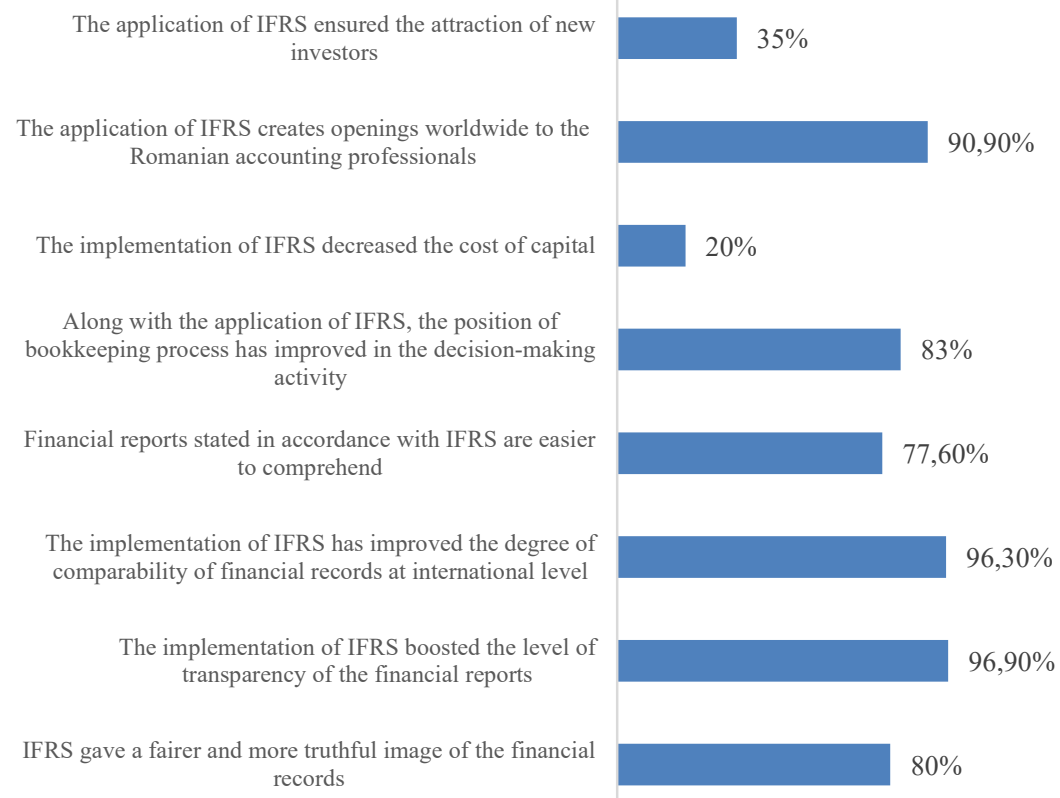

Figure no. 5. Managers' opinion regarding the benefits of implementing IFRS

Merging the responses obtained relate to both the advantages and the disputes of implementing IFRS, we have noticed that the interviewed managers do not approve that the adoption of IFRS reduces capital costs (only 20\% come to an agreement with this declaration). In addition, other current expenditures linked to the conversion and the implementation of IFRS did not decrease, but, conversely, recorded a substantial growth, such as: expenditures with withdrawals and changes in financial reports, expenses with employees trainings, expenses with control and audits, expenses with the reorganization of the company's operational and IT infrastructure. These issues also resulted from responses collected to the query about the challenges faced by companies in implementing IFRS (Figure 6). 
Irina Diana IORDACHE | Lumen Proceedings 13 | NCOE4.0 2020

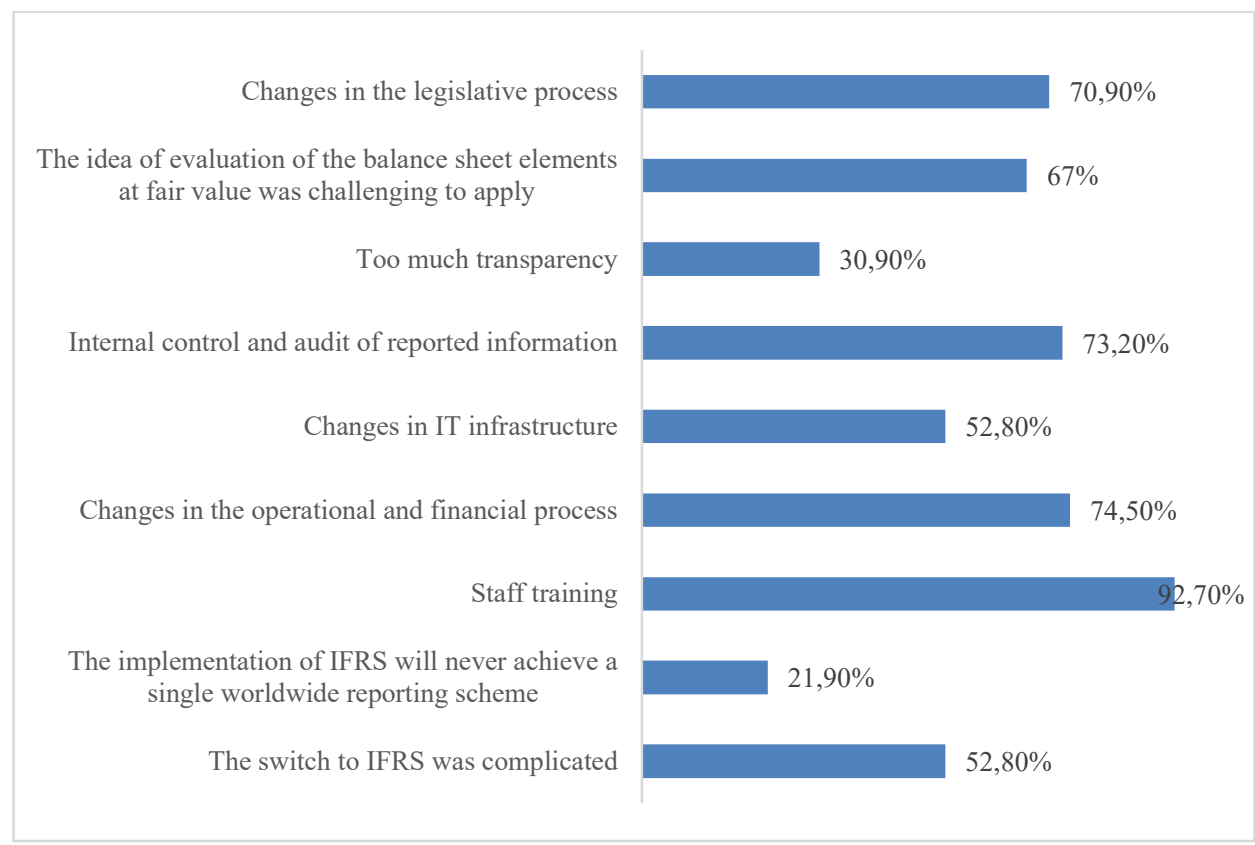

Figure no. 6. Managers' opinion regarding the challenges faced in the process of adoption and application of IFRS

Also, the answers to the question linked to the challenges associated to the application of IFRS are very varied (Figure 6). For instance, 53\% of the interviewed managers believe that the conversion to IFRS is complex and difficult, 93\% believe that personnel teaching is a major cost challenge, $74.5 \%$ were sceptical about reorganizing operational and financial processes, and $53 \%$ were anxious to deviations triggered by the IT infrastructures. Taking into consideration the awareness of our respondents about the struggles faced when adopting IFRS, we can accept hypothesis 3.

\section{Discussions}

The system created by the international reporting standards is, of course, in the process of constant revision and development, following the evolution and limitations expressed in practice. For instance, as is wellknown, IFRS 15 "Revenue from contracts with customers" and IFRS 16 "Leases" have been released and are applied currently worldwide. These are events that bring in technical and operative issues for specialists. Consequently, these standards will be the topic of upcoming studies. 


\section{Conclusions}

From what is presented in our study, a first and very important conclusion should be drawn, namely that the issue of improving accounting practices is, in recent decades, in a real area of conflict, generated by the innovation of the international conceptual accounting framework in relation to the resilience of the national accounting conceptual framework. Thus, the most important users of financial information (creditors, respectively investors), have started a series of requests regarding the form and content of the financial statements of companies, concerned, at the same time, to find solutions. These concerns have materialized through proposals to reduce fiscal influences, various attempts to regulate the accounting profession, and a number of language proposals in reporting financial results.

Following these steps, the expected results were not long in coming, as many countries have adhered to International Financial Reporting Standards, thus triggering a real reform of national accounting practices. Consequently, we can now call the traditional accounting treatments overshadowed by the idea of a "new accounting". An accounting that has as main concern the placement of capital investors and creditors at the top of the pyramid of information needs.

Therefore, a second conclusion we draw is that the current business environment and users of financial information are becoming increasingly aware of the role of the professional accountant at the level of an entity and in the economy in general.

They must strike a balance between meeting deadlines and providing sufficiently credible information, given that an excessive delay in obtaining and reporting financial information leads to a loss of relevance.

At the same time, providing timely information involves reporting all the elements and aspects of an event or transaction, even before they are established, so we can affect credibility. Otherwise, although the information may provide more credibility, there is still the issue of utility, which can be reduced for users who make decisions without knowing the whole issue.

We thus deduced the need for a balance between credibility and relevance, in the process of satisfying the needs of users of financialaccounting statements.

\section{Acknowledgement}

This work is part of the project „Development of tertiary education in support of economic growth-PROGRESSIO", project code 
Irina Diana IORDACHE | Lumen Proceedings 13 | NCOE4.0 2020

POCU/380/6/13/125040, project co-financed by the European Social Fund through the Human Capital Operational Program 2014 - 2020.

\section{References}

[1] Achim MV, Borlea SN, Mare C. Corporate Governance and Business Performance: Evidence for the Romanian Economy, Journal of Business Economics and Management. 2016; 17(3): 458-474

[2] Balsmeier B, Vanhaverbeke S. International financial reporting standards and private firms "e access to bank loans, European Accounting Review. 2016; 15 (1): $1-30$

[3] Farcane N, Blidişel RG, Bunget, OC, Dumitrescu A. Perceptions Regarding the Impact of IFRS 15 - Illustrative Examples Step by Step, Audit Financiar. 2019; vol. XVII, 2 (154)/2019: 283-297.

[4] Trabelsi R.. International accounting normalization and harmonization processes across the world: History and overview, GSTF Business Review. 2015; 4, (2): 54-61. 